\title{
THE POTENTIAL FOR ADOPTING STRATEGIC ENVIRONMENTAL ASSESSMENT (SEA) IN EGYPT
}

\author{
Ibrahim Hegazy \\ Department of Architecture, Faculty of Engineering \\ EI Mansoura University.
}

Hossam Samir lbrahim

Regional Development Department, Faculty of Regional \& Urban planning

Cairo University.

\begin{abstract}
The achievement of sustainable development demands a close integration between environment and development. The evidence is that in developing countries (Egypt, as an example) the gap between the need for environmental protection and development processes is widening rather than closing. Intensive research programmes are needed, for instance in the field of sustainable development and environmental management, to narrow that gap. Despite the fact that Egypt has achieved considerable progress in environmental management, in particular in establishing an EIA system as a management tool for achieving acceptable forms of environmentally sound development and sustainability; it is argued that there are various EIA constraints. It is also noted that the natural environment in Egypt has continued to be heavily degraded. Therefore, this paper advocates the adoption of strategic environmental assessment as a means of achieving sustainable development in planning practice. SEA is considered to be the machinery for achieving close integration between the environment and development processes in Egypt. This paper mainly aims at investigating the Egyptian environmental context to reveal the potential for SEA to be introduced in environmental management to achieve more sustainable development.
\end{abstract}

\section{Keywords}

Egypt, Strategic environmental assessment, EIA, sustainable development

\section{الملخص}

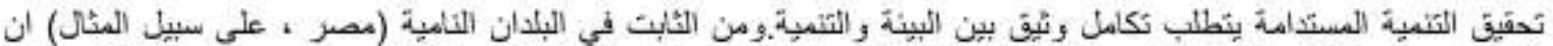

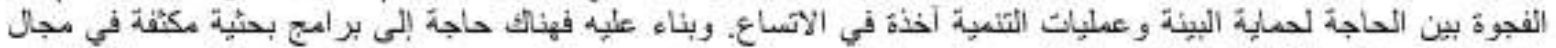

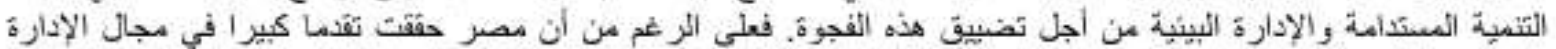

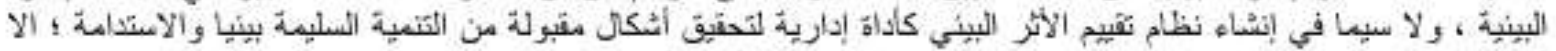

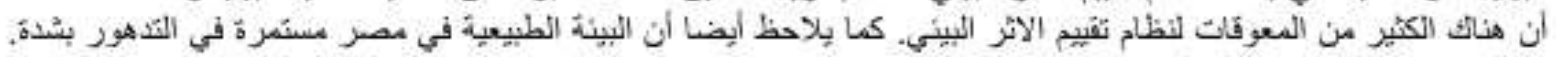

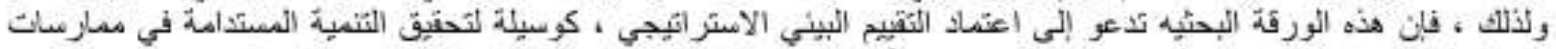

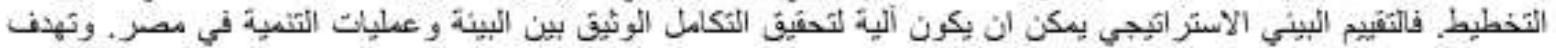

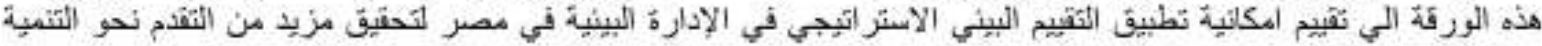




\section{INTRODUCTION}

In Egypt, rapid industrialization, urbanization and population growth are among the most significant reasons for increasing environmental problems, including the degradation of natural resources. Egypt, like many other countries, has conflicting objectives of pursuing economic growth and preserving the environment. The demand for new resources to provide livelihood as well as social and physical infrastructure and services for urban areas is expected to put more pressure on the environment. to cope with these conflicting demands, Egypt has enacted a substantial body of environmental and environment-related laws, decrees and regulations addressing various aspects of environmental protection and natural resources management (Abdel Wahab, 2003), along with various sectoral laws which consider environment protection as a main priority in development (WB, 2005).

Environmental impact assessment (EIA), as a tool integrating environmental aspects in decision making at project level, has been widely practised in Egypt for more than 15 years. Nevertheless, it seems ineffective in protecting natural resources. There are many challenges, as briefly classified in Box 1 , associated with development processes that still face the environment.

Box (1): Challenges facing development processes in Egypt

- Deterioration of natural resources due to rapid
economic growth which has been created at the
expense of natural resources in rural areas.
- Diffusion of massive informal development areas and
lack of the tools necessary to guide urban growth
- Poor quality of urban environment and the rapid
growth of population

Source: WB, 2005

EIA largely reacts to development proposals; it does not proactively anticipate and guide them (Glasson et al., 1994; Lee and Walsh, 1992). ElAs take place after many strategic decisions have already been made, and they often address only a limited range of alternatives and mitigation measures as a result of actions taken previously.

There have been many attempts from the Egyptian government to develop a planning system that pays more attention to the environment, and considers environmental aspects at the earliest possible stage in the decision-making process. It was even declared that the strategic objective of environmental policy in Egypt is to introduce and integrate environmental concerns into all national policies, plans, programmes, and 
projects (EEAA, 2002). Moreover, article 59 of the Egyptian constitution, added in 2007, stipulates that, "environment protection is a national duty; the law regulates the necessary measures for maintaining a good environment". In this context, this paper advocates the adoption of strategic environmental assessment as a mean to achieve this objective, and to achieve more sustainability in development processes.

This study is based upon a detailed investigation of the current environmental conditions in Egypt and the potential for establishing strategic environmental assessment (SEA) in the country. It relies on a review of relevant literature and compilation of environmental legislation, reports and relevant documents. Information was also obtained through interviews conducted with professional staff at the Egyptian Environmental Affairs Agency (EEAA) and its regional branch offices, specialist agencies responsible for the environment, EIA practitioners, and academic members of universities and research institutes. The survey was based on semi-structured interviews, including both open-ended and closed questions. It was important to acquire qualitative information to gain a more in-depth understanding of the subject and discover respondents' own interpretations of the issues under investigation.

The present paper briefly provides an overview of SEA and its benefits, and introduces the evaluation criteria to investigate the potential for the adoption of SEA in the Egyptian context. It then provides an analytical evaluation of the current environmental conditions in Egypt and identifies the context elements that may support the possible consideration of environmental issues at the strategic level. The paper then discusses the possible adoption of SEA as a tool to promote sustainable development.

\section{EVALUATION CRITERIA METHODOLOGY}

A set of evaluation criteria was used to investigate the Egyptian environmental context. The criteria are based on evaluation criteria proposed by Briffett et al. (2003). These criteria are grouped into six categories, namely, political will, legal mandate, the capacity of environmental institutions, EIA implementation and technical know-how, environmental education and awareness and, finally, social acknowledgement and the role of civil society (see Box 2).

The current research methodology also includes interviewing EIA practitioners. The opinions of those involved in the EIA process provide valuable input for the evaluation process. Interviewees included EIA practitioners at the EEAA and its regional branch offices (RBOs), local authorities, environmental consultants and university staff. Given the particular aim of this research, semi-structured interviews including both openended and closed questions were considered the logical choice. The questionnaire was developed on the basis of the literature review (Simmons, 2001; Bryman, 2004; Creswell, 2008) as well as by conducting a pilot interview with three environmental consultants. 
Box (2): Context criteria for supporting the potential of SEA

\section{1) Political will}

1.1) Environmental policy or plan

1.2) Official statements in support of the consideration of environmental issues at the strategic level

1.3) National environmental charter or code

\section{2) Legal mandate}

2.1) Integrated environmental law

2.2) Mandatory EIA legislation

3) Environmental institutions' capacity

3.1) A well-defined institutional structure responsible for the environment

3.2) Ministry of the environment

3.3) Independent environmental protection agency

3.4) Regional environmental planning and decentralisation

3.5) Clear competences/responsibilities

4) EIA implementation and technical know-how

4.1) Requirements for EIA:

- mandatory screening

- mandatory scoping

- baseline data

- impact prediction

- mitigation

- monitoring

- independent review

4.2) ElA guidelines

4.3) A professional association for environmental assessment consultants

4.4) Training support

5) Environmental education and awareness

5.1) A formal education system at different stages and levels of education

5.2) Environmental awareness dissemination among the public

6) Social acknowledgement and the role of civil society

6.1) Mandatory public participation

6.2) Environmental NGO consultation

Source: Adopted from Briffett et al., 2003

Out of 40 EIA practitioners approached, 21 were willing to be interviewed: $10 \mathrm{EIA}$ practitioners at the EEAA, RBOs and Environmental Management Units (EMUs); five employees of environmental consultant firms; and six members of academic staff (see Appendix 1). 


\section{THE POTENTIAL FOR SEA WITHIN THE EGYPTIAN CONTEXT}

In this section an analytical assessment based on the fieldwork identifying the elements of the Egyptian context that support the potential for adopting SEA as a tool to achieve sustainable development in environmental management is presented.

\subsection{Political will}

Political will is defined in this study as one that promotes and supports SEA at the highest level of decision making. Strong political support is considered as one of the most important factors in the development of an effective SEA system (Partidario, 1996). In situations where key decision makers consider environmental concerns to be irrelevant to decision making, SEA may not be taken seriously as a part of decisionmaking mechanisms. In order to change this situation, strong political support for SEA needs to be in place. Political support from government is required to promote the application of SEA and encourage due consideration of SEA findings when making final policies, plans and programme (PPP) decisions.

Like most developing countries, Egypt has been undergoing rapid urbanisation and industrialisation. This has been followed by a rapid shift of population from rural to urban areas as the economy moves from an agricultural to an industrial economic structure. Moreover, Egypt is progressing in many planning sectors. The main sector that has received a high percentage of Egyptian investment is urban development planning. Nevertheless, it is argued that there have been many undesired effects on the environment resulted from these development processes. In fact, it could be said that urban development, as a result of national policy over the past three decades, has been associated with the extensive exploitation of natural resources for urban growth.

After 25 January 2011 Revolution, it is evident that there is a strong need for more urban development processes, aiming to absorb population growth in the desert, with increasing recognition that uncontrollable urbanization may well give rise to various issues such as overexploitation of natural resources, ecosystem destruction, environmental pollution and large-scale climate change. Since sustainable development or sustainability has been highlighted as an essential principle in urban development planning, it is deemed necessary to modify the existing urban system so as to cope with the challenges urban planning is being confronted with and realize the purpose of urban sustainability. One approach to this could be the adoption of a system for integrating SEA into urban planning processes as part of an integrated approach to sustainable development.

Based on this understanding, Egypt has demonstrated a strong political commitment for achieving sustainable development since 2002 when the National Environmental Action Plan (NEAP) was issued as a significant document representing an attempt to incorporate environmental issues in the government's political agenda. NEAP is 
considered as a plan of strategic actions covering the period to 2017, and aims to integrate environmental concerns into all national policies, plans, programmes, and projects (Zetter and Hassan, 2002). Further to this, in approving the NEAP, both the Prime Minister and the Minister of State for Environmental Affairs note in their forewords that the goal of sustainable development linking development with environmental protection is the key to Egypt's future.

Furthermore, President Mubarak 2002, in a meeting with the Cabinet Council to discuss the environmental strategy for Egypt, indicated that the "Environment is not a luxury business, but environmental protection is a national duty" (WB, 2005). He also confirmed that the environmental dimension should be integrated into the development policies, programmes and projects in order to achieve sustainable development. With respect to this, although most interviewees considered this as a promising step towards the realization of a stronger environmental commitment of the Egyptian government at the highest levels, they doubted that politicians will support the application of SEA. $57 \%$ of interviewees admit that it is not easy to persuade politicians to support SEA, since they may fear that SEA will limit their political choices. The interviewees believed that without complete mandatory provisions, it is hard to promote SEA.

\subsection{Legal mandate}

Legal mandate is important for ensuring that SEA could be set up in a consistent manner, giving certainty to the actors involved in both the SEA and PPP processes (Fischer, 2007). Legal mandate is normally laid out in environment-related legislation, regulations or directives. Briffett et al. (2003) argue that wherever a legal mandate is in place, formal SEA provisions could be effectively established. This gives its results priority in the decision-making process.

In this context, Egypt has a long history of environmental legislation that goes back to 1947 although major problem lies in weak regulatory compliance and enforcement (Abdel Wahab, 2003). The record in Egypt for implementing and enforcing environmental laws was not very successful. With limited exceptions, violations of environment-related laws went undetected and requirements went often unendorsed especially with the public sector polluting enterprises. The main impediments to effective and meaningful implementation and enforcement of environmental and environment-related laws are due to the fragmentation among regulatory institutions, licensing agencies, police authorities ...etc., at both national and governorate levels to the effect that no single institution can apply enforcement actions effectively (WB, 2005).

It was not until 1994 that Environment Protection Law, a unified law dealing with all the media of the environment (Air, Land, and Marine Water), was promulgated. The law mandates the use of the EIA process in the context of licensing new, expansion, or 
rehabilitation projects as specified in the Law's Executive Regulations. $81 \%$ of interviewees considered that the enactment of Environment Protection Law 4/1994 addressed several significant legislative gaps neglected by earlier legislation in the legal framework for environmental protection. Law 4/1994 presents an example for the amalgamation of all the environmental legislations into one act.

Despite these positive impacts, the enactment of Law No. 4/1994 had many weaknesses. As a consequence, the Egyptian government has recently promulgated Law No. 9/2009 which amends some provisions of Law No. 4/1994. Law No. 9/2009 enacts the main principles underlying environmental management and protection initiatives. It seeks to achieve environmental protection through improvement of proper institutional, legislative and technical frameworks at the local, regional and national levels.

Overall, it is therefore evident that most interviewees felt that SEA will not be effectively and widely conducted without a strong legal basis due to its high level of strategic importance. Many interviewees argued that the Environmental Protection Law is the most appropriate legislation for the incorporating of the SEA provisions. However, it is generally accepted that the law requires to support timely and effectively the enforcement. In addition, it needs to emphasis close cooperation, continuous dialogue, and an effective partnership with all concerned central and local government entities. Nevertheless, most interviewees believed that strong political will with a legal basis is necessary to form an effective package to adopt and enforce SEA application.

With respect to EIA system, it was formally introduced in the Law No. 4 of 1994 as a management tool for helping to achieve acceptable forms of environmentally sound development and sustainability. Law 9/2009 includes some modifications to the Egyptian EIA system; these include administrative arrangements and the specification of roles for those involved in EIA, requirements for mitigation measures and monitoring systems that require reporting by the developer. A penalty for lack of submission of an environmental impact assessment and failure to keep yearly environmental records in each establishment will also be imposed (Law 9/2009). Moreover, the environmental law established a public complaint system to encourage public monitoring and protection of the environment (Badr, 2009). Briffett et al. (2003) admitted that EIA legislation may be a supportive basis for SEA. In this context, many interviewees argued that the use and application of EIA is relatively strong across the country to a greater or lesser extent. Its legislative provisions are well-defined in the Egyptian environmental law and, due to the long-time process in case of introducing new legislation for SEA in Egypt; these provisions could be extended to cover the environmental assessment for policies, plans and programmes.

\subsection{Environmental institutions' capacity}

The institutional capacity and organisational aptitude of environmental institutions are of importance if the SEA process is to be implemented in an effective manner 
(Partidario, 1996). Institutional capacity can be indicated by the presence of a Ministry of the Environment or an independent environmental agency, which is responsible for environmental protection and the implementation of environmental assessment processes (Briffett et al., 2003). The country's reports (EEAA, 2007 and 2008) show that Egypt possesses a well-defined institutional structure responsible for environmental issues (Figure 1).

Figure (1): The environmental institutional structure in Egypt

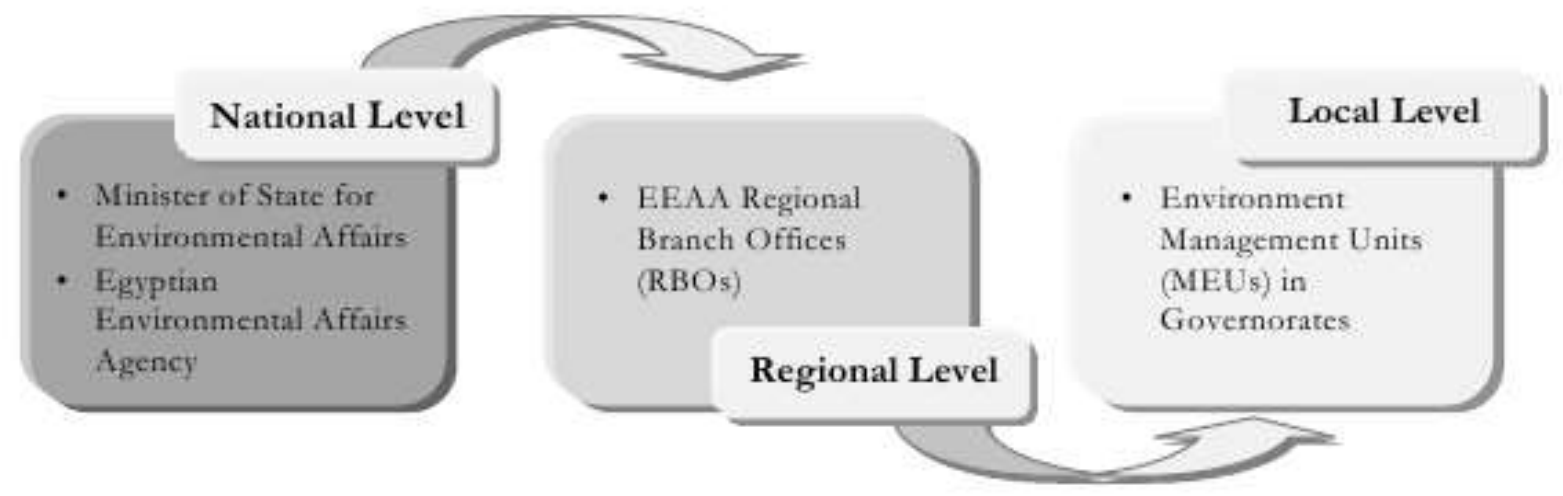

The Ministry of State for Environmental Affairs (MSEA) is responsible for overseeing the government's efforts to protect the environment and promote sustainable development. The MSEA plays a central role within the government of Egypt for the definition of environmental policies and the setting of environmental priorities. Furthermore, the Egyptian Environmental Affairs Agency (EEAA) presents the executive arm of the MSEA. The EEAA has a coordinating and horizontal role among all ministries (Law 4/1994; Law 9/2009).

Institutional capacity may also be determined by examining whether there is a clear decentralisation through regional and local authorities, or not (Briffett et al., 2003). A tiered system allows higher order policies, plans and programmes (PPPs) to set the context for actions at lower levels (Partidario and Clark, 2000; Fisher, 2007). In this context, the MSEA and EEAA are continuously developing the capacities and partnerships necessary to strengthen the network of Regional Branch Offices (RBOs), and the capacities of the Environmental Management Units (EMUs) of the governorates. Furthermore, a number of training courses and on-the-job training from capacitybuilding projects supported by a number of donors, targeting both RBO and EMU staff members, were conducted (EEAA, 2007).

Nevertheless, few local planners admitted that the EMUs still need additional staff, training, office and technical equipment. They also believed that to be able to perform their functions effectively and promote decentralization, all EMUs would need to be raised to a higher institutional level, a general directorate level, which would then increase their effectiveness. 
The most critical barriers which may influence the effective SEA application as considered by $71 \%$ of interviewees are the poor institutional coordination and nonintegrated planning system. They believed that the current communication channels between agencies seem to be insufficient. This poor coordination results in nonintegrated planning systems, objectives, methodologies and outcomes. One high-ranked consultant claimed that it is essential to achieve a willingness to co-operate in the SEA process, so ensuring that those involved perceive themselves as real actors in policy and plan making.

\subsection{ElA implementation and technical know-how}

This context element looks at the ability for applying the environmental assessment process, and the extent to which the EIA is implemented effectively. In Egypt, the administrative arrangements and roles of different agencies in the EIA are defined in the regulations. The EEAA is the main body for EIA although sectoral ministries and governorates are the competent administrative authorities which possess the executive power in relation to development authorisation (Ahmed and Wood, 2002). The central EIA department of the EEAA is responsible for supervising the screening process, managing the review of EIA reports, taking decisions on the acceptability of EIA reports and giving an opinion on the proposals (Badr, 2009; WB, 2005). Further to this, the procedures of the EIA process are also well defined; screening and scoping are mandatory in the Egyptian EIA. The EIA report should include a discussion of predicted impacts and proposals for mitigation measures. An independent consultant is assigned to review and make recommendation to the EEAA for making decisions.

Since 1994, the ElA system in Egypt has progressed significantly. Efforts by the EEAA have led to steady improvements in all aspects of the EIA system, from preparation to review and decision making. Accordingly, since 2000, it has experienced a dramatic increase in the number of EIA studies (see Figure 2).

Figure (2): Number of ElA studies in Egypt

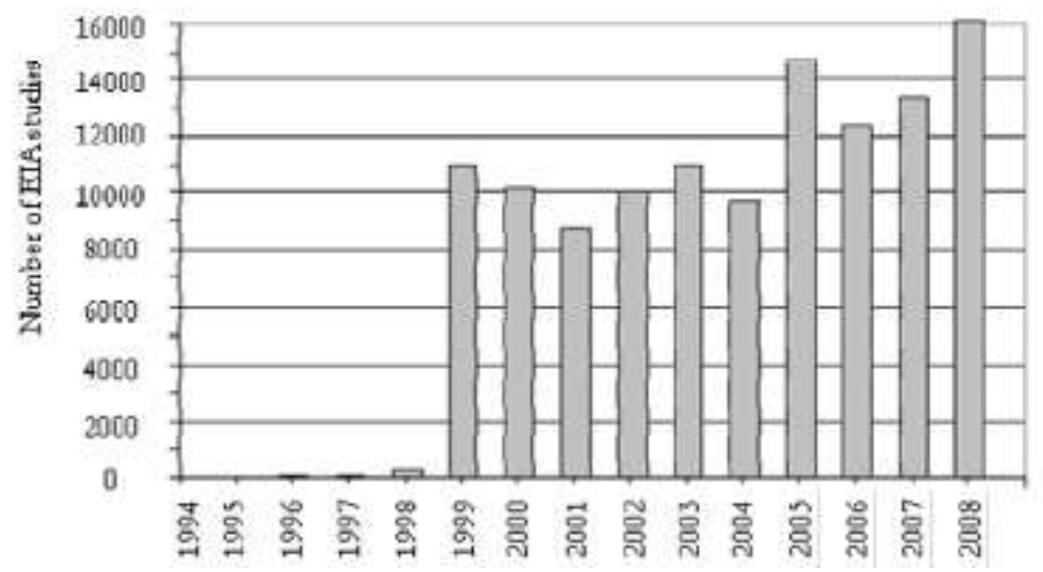


Technical know-how is one of the major factors supporting an effective SEA application. Technical know-how is associated with environmental assessment activities implementation. Briffett et al. (2003) argues that technical know-how relates to the ability to design, control and monitor EIA activities. The availability of supporting EIA guidance and satisfactory technical support are good indicators of effective technical know-how.

In this context, the EEAA, with the support of the Danish International Development Agency (DANIDA), has published general guidelines for assisting the EIA process (METAP, 2000). These guidelines are described in the procedures for EIA identified in law and its executive regulation. Several sectoral guidelines have also been developed, with assistance from the Environmental Assessment and Management (SEAM) project funded by the UK's Department for International Development (WB, 2005). These include EIA guidelines for municipal wastewater treatment works; cement works; ports and harbours; industrial zones; urban development projects; oil and gas facilities and coastal tourism activities. A second edition of the above guidelines was issued in January 2009 to include more updated and detailed procedures for EIA system (EEAA, 2009). However, interviewees argued that further guidelines are needed to give developers and consultants fuller guidance on potential impacts and appropriate impact prediction techniques.

A clear understanding of needs, objectives, values, processes and methods is needed to support an effective EIA application (Fischer, 2007). Training courses and workshops play an important role in understanding how to apply and control the environmental assessment processes. In this context, Egypt has a core of well-trained academics and researchers that are involved in the environmental field. Many universities and research centres are providing consulting services either through their specialized research centres, or through the establishment of private consulting firms (WB, 2005). There are well-established EIA training programmes organised by academic institutes such as the Ain Shams, Cairo, Alexandria and EI Mansoura Universities, which contribute to building institutional capacity (Badr, 2009)..

Moreover, Egypt received most international funding for training. For example, many international donor agencies, such as the World Bank and the British and Danish aid agencies, have funded different EIA training and capacity-building programmes (Badr, 2009). Among these was the METAP EIA project, which was funded by the World Bank and involved institutional strengthening of the EIA system. $62 \%$ of interviewees claimed that, as in many countries in the developing world, most EIA training funded by multilateral or bilateral donor agencies has been conducted on an ad hoc basis with very little coordination between the various training programmes. Overall, therefore it is evident that most interviewees felt that the degree to which environmental assessment processes are conducted would depend on the efficiency of the technical know-how and how well it is provided. They also considered that the current experience of EIA may promote the technical know-how to implement the SEA process. 
To improve the quality of EIA performance and to ensure the effectiveness of its outcomes, Fuller (1999) acknowledged that a professional recognition scheme is needed to ensure that EIA processes are undertaken only by appropriately qualified and experienced practitioners. In this respect, Law No. 9 of 2009 mentions the establishment of a higher accreditation committee, to be headed by the Minister of the Environment, which will address environmental consultants' registration and certification. In addition, the executive regulation of this law defines the procedures and requirements for registration and accreditation.

Although Egypt has achieved considerable progress in establishing an EIA system, it is argued that there are various EIA constraints, as following (Ahmed and Wood, 2002; WB, 2005; Badr, 2009):

- Public participation is not mandatory and public hearings are mainly held for mega projects.

- The availability and accuracy of information defining environmental baseline conditions is one of the main challenges facing the effective implementation of the EIA process.

- There are no systematic review criteria to be used by EEAA staff; the review process is based mainly on reviewers' experiences, as well as on personal judgment.

- The legal requirements for reporting by the developer and monitoring by the EEAA need to be implemented more fully than at present.

\subsection{Environmental education and awareness}

Environmental education is a learning process that increases people's knowledge and awareness about the environment and associated challenges, develops the necessary skills and expertise to address the challenges, and fosters attitudes, motivations and commitments to make informed decisions and take responsible action (UNESCO, Tbilisi Declaration, 1978). Briffett et al. (2003) argued that environmental education may be promoted through the formal education system at primary, secondary and collegiate levels or through professional mechanisms.

In this respect, Egypt's major universities have graduate programmes in environmental planning (WB, 2005). Furthermore, the major research centres such as the National Research Centre of the Egyptian Academy of Scientific Research and Technology, the Agriculture Research Centre of the Ministry of Agriculture and Land Reclamation and the National Water Centre of the Ministry of Water Resources and Irrigation provide many related environmental courses for planners and developers with well-trained staff and excellent facilities. In despite of that there is a B.Sc. programme in environmental science at the University of Alexandria, many interviewees claimed that well-established programmes are recommended to be established in most Egyptian universities at both, 
undergraduate and postgraduate levels. They believed that environmental education enhances critical thinking, problem-solving and effective decision-making skills to weigh various sides of an environmental issue to make informed and responsible decisions.

With respect to awareness dissemination among the public, the MSEA, together with its executive institution, the EEAA, regard this issue as a priority, realizing the significant role public awareness can play in promoting sound environmental practices. All interviewees argued that awareness is an important tool for the sensitisation of public opinion to environmental issues and challenges. They believed that public opinion may be effective if it creates a strong enough pressure on the decision-makers. In this context, the successful partnership between the MSEA and EEAA on the one hand, and the Media on the other was carried further. In this respect, programmes targeting the public were conducted, including the broadcasting of 13 environmental television programmes and 35 radio programmes, as well as a number of competitions. Moreover, 28 national newspapers and magazines are now engaged in environmental awareness, in close cooperation with the MSEA and EEAA, featuring regular environmental pages (EEAA, 2008). Various EEAA publications and brochures were prepared and disseminated through national and regional environmental exhibitions and events. Yearly public events also organized by the MSEA and EEAA (WB, 2005) include the International Ozone Day (16th September), Earth Day (22nd April) and the International, Arab and National Environment Days (5th June, 14th October, and $27^{\text {th }}$ January, respectively).

\subsection{Social acknowledgement and the role of NGOs}

Social acknowledgement partly derives from the educational process and is considered both from public participation that exists, and the degree to which public issues are considered in the environmental assessment (Briffett et al., 2003). However, there is a multitude of rationales for public participation in the EA process. Among them are enhancing the transparency of decision-making processes and enhancing the completeness, validity and reliability of the relevant information (Heiland, 2005). Furthermore, public participation promotes openness and accountability, fairness and equity and defends human rights within PPP making. Indeed, the more environmental awareness and public acknowledgement exists, the more SEA development is achieved.

With respect to the Egyptian case, the law of environment does not have any provisions related to public participation. Public hearings are conducted only for certain projects funded by international organisations (Badr, 2009). Consultants interviewed argued that, since public participation is not mandatory, it is often ignored and is being undertaken only for certain projects. Approximately half of the interviewees indicated that an adequate response could be obtained from the public during consultation, but that public opinion is not always considered. 
More than $70 \%$ of interviewees believed that a continuous programme of environmental awareness-raising for the public is needed. The public needs to be aware of a project's environmental consequences and understand their responsibility towards the EIA process. Moreover, they should be provided with the opportunity to comment on the ElA statement prior to a decision being made on the proposal.

With respect to the role of non-governmental organisations, Egypt has a number of NGOs actively participating in the environmental arena. Estimates are that more than 270 environmental NGOs are working on various aspects of environmental management in Egypt, on issues ranging from public awareness to waste collection and community self-help programmes (EEAA, 2008). However, very few environmental NGOs have grass roots linkages to influence the public or the community they serve (WB, 2005). NGOs have been increasingly involved in project implementation, in public debate and also in ensuring compliance with the environmental laws.

Law No. 4/1994 and its amendments in Law No. 9/2009 recognise the importance of NGOs in environmental management. Three representatives from the NGO community are required on the Board of the EEAA. The law provides the authority for NGOs to bring legal action to enforce its environmental requirements. The MSEA and EEAA are encouraging NGOs to take a more active role at the grass roots level in order to serve their communities. Moreover, a special unit was established at the EEAA to enhance NGO collaboration.

\section{DISCUSSION}

Although a strong political commitment by the Egyptian government towards achieving sustainable development will surely support the adoption of SEA, its successful performance will necessitate changing the mind-sets of top personnel. One advantage of the Egyptian environmental context is that Law No. 4/1994 and its amendments in Law No. 9/2009 present an example for the amalgamation of all environmental legislations into one law, which all interviewees considered to be the most appropriate foundation for SEA provisions.

Results show that the use and application of EIA is relatively strong, and Evidence of well-established EIA procedures were found, but translation of paper to action was found wanting. However, the environmental context review has confirmed many common challenges that give rise to inadequate EIA practice. There is a possible case for saying that an EIA may need to be modified to suit particular localized standards and expectations, but there is less demand for removing it as a process because of the many benefits that can be gained including increased educational awareness and changes in attitudes. 
While the establishment of improved institutional capacity is undoubtedly considered to be a potential support for the adoption of SEA, there is also the problem of not having sufficient power and influence over all sectors, ministries and departments to achieve effective implementation in practical terms. An increasing number of government servants, academics and practitioners are aware of SEA and sustainability as a policy option, but they do not necessarily fully understand the concepts. Many of the people interviewed confirmed that Egypt is actively involved in protecting the environment through the implementation of plans and the preparation of relevant and appropriate programmes.

Despite of building up educational training courses for public and private practitioners, as well as, adopting strategies for integrating environmental assessment as a crosscutting issue into educational curricula at all levels of education, additional support is still essential for promoting consciousness of the potential benefits of environmental assessment at higher level of strategies.

\section{CONCLUSION AND RECOMMENDATIONS}

The research enquiries have revealed some interesting results. The potential for the future adoption of SEA was generally found to be good because of the widespread recognition of the importance of environmental awareness. This is particularly confirmed in the increasing commitment of government towards sustainable development, the proliferation of environmental non-government organizations and the governments' improved involvement with the concept of sustainability. The presence of a mandatory EIA system has not prevented many abuses occurring, and should SEA become mandated for in the future, much more integration and coordination between ministries and between the private and non-government sectors will be needed. In our view, the SEA concept is likely to have much greater take-up in Egypt where a strong centralized bureaucracy exits because decisions taken at the highest strategic level are more effectively transmitted downwards.

One of the recommendations for improvement is the possible use of SEA, not as a substitute for EIA, but more as an upfront supplement. Where serious environmental threats are identified in proposals at the strategic stages of policies, plans and programmes, these can be more easily modified or designed out of the development proposals so as to reduce the number of project-based EIAs. Moreover, SEA has many advantages and these will increasingly be recognized. They include the influences on the planning and design stages in urban development planning, the technological choices and policy options to be pursued and the ability to recognize and avoid or mitigate serious adverse cumulative impacts

In conclusion, it may therefore be stated that the potential for future for take-up of SEA is high, although its format and scope may need to be adapted to fit the country's 
needs. The work presented in this paper provides a useful example that any developing country can take and adapt. What works in one country may not work in another, particularly where the political, legal and administrative frameworks are different. The ultimate advantage of bringing the environmental agenda to a strategic level must surly is beneficial and influential in improving the current state of the environment.

\section{APPENDIX 1. INSTITUTIONAL AFFILIATIONS OF INTERVIEWEES}

EIA Centre, Environmental Management Sector at the EEAA

El Mansoura Regional Branch Office (RBO) of the EEAA

Suez Canal Regional Branch Office (RBO) of the EEAA

Environmental Management Unit at Dakahlia governorate

Environmental Management Unit at New Damietta City

El-Nile for Scientific and Environmental Consultants

Green Environment Consultants

Cairo University

El Mansoura University

Suez Canal University

\section{References}

Abdel Wahab, R (2003). Sustainable development and environmental impact assessment in Egypt: Historical Assessment. Environmentalist, 23(1), 49-70.

Ahmad, B and C Wood (2002). A comparative evaluation of the ElA systems in Egypt, Turkey and Tuisia. Environmental Impact Assessment Review, 22(3), 213-234.

Arab Republic of Egypt (1995). Law No. 4 of 1994 on the Protection of the Environment and its Executive Regulations. Cairo: Arab Republic of Egypt (ARE).

Arab Republic of Egypt (2009). Law No. 9 of 2009 Amendment of Law No. 4 of 1994 on the Protection of the Environment and its Executive Regulations. Cairo: Arab Republic of Egypt (ARE).

Badr, E (2009). Evaluation of the environmental impact assessment system in Egypt. Impact Assessment and Project Appraisal, 27(3), 193-203.

Briffett, C, J Obbard and J Mackee (2003). Towards SEA for the developing nations of Asia. Environmental Impact Assessment Review, 23(2), 171-196.

Bryman, A (2004). Social research methods. Oxford: Oxford University Press.

Creswell, J (2008). Research Design: Qualitative, Quantitative, and Mixed Methods Approaches, 3rd ed. London: Sage Publications.

EEAA (2002). The national environmental action plan of Egypt 2002/17. Cairo: Egyptian Environmental Affairs Agency (EEAA). 
EEAA (2007). The environmental annual report 2007. Cairo: Egyptian Environmental Affairs Agency (EEAA).

EEAA (2008). The environmental annual report 2008. Cairo: Egyptian Environmental Affairs Agency (EEAA).

EEAA (2009). Guideline for Egyptian environmental impact assessment principles and procedures, 2nd edn. Cairo: Egyptian Environmental Affairs Agency (EEAA).

Fischer T (2007). Theory and practice of strategic environmental assessment. London: Earthscan.

Fuller, K (1999). Quality and quality control in environmental impact assessment. In: Handbook of Environmental Impact Assessment, Vol. 2. Environmental Impact Assessment in Practice: Impact and Limitations, ed. J Petts. Oxford: Blackwell, 55-82.

Glasson, J, R Therivel and A Chadwick (1994). Introduction to environmental impact assessment. London: UCL Press.

Heiland, S (2005). Requirements and methods for public participation in SEA. In: Implementing strategic environmental assessment, ed. M Schmidt. German: Springer, 35-70.

Lee, N and F Walsh (1992). Strategic environmental assessment: an overview. Project Appraisal, $7(3), 126-36$.

METAP (2000). Evaluation and Future Development of the EIA System in Egypt: A Report Prepared under the METAP EIA Institutional Strengthening Project. Manchester: Mediterranean Environmental Technical Assistance Programme (METAP), Manchester University EIA Centre.

Partidario M and R Clark (2000). Perspectives on strategic environmental assessment. New York: Lewis.

Partidário, M (1996). Strategic environmental assessment: Key issues emerging from recent practice. Environmental Impact Assessment Review, 16(1), 31-55.

Simmons, R (2001). Questionnaires. In Researching social life, ed. N Gilbert, pp. 85-104. London: Sage.

UNESCO (1978). Tbilisi Declaration. United Nations Educational, Scientific and Cultural Organisation: Intergovernmental Conference on Environmental Education.

WB (2005). Arab Republic of Egypt: Country Environmental Analysis. Cairo: World Bank.

Zetter, R and A Hassan (2002). Urban economy or environmental policy? The case of Egypt. Journal of Environmental Policy and Planning, 4(2), 169-184. 